\title{
Comprehensive Intersystemic Assessment Approach to Relieve Psychogenic Erectile Dysfunction: A Review
}

\author{
Cennikon Pakpahan ${ }^{1}$ (D) Agustinus Agustinus ${ }^{1 *}$ (D), Darmadi Darmadi ${ }^{2}$ D \\ ${ }^{1}$ Department of Biomedical Sciences, Faculty of Medicine, Universitas Airlangga, Surabaya, Indonesia; ${ }^{2}$ Department of Internal \\ Medicine, Faculty of Medicine, Universitas Sumatera Utara, Medan, Indonesia
}

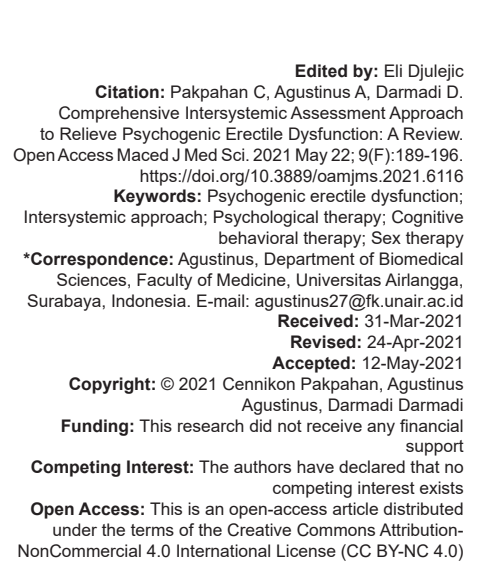

Abstract

Psychogenic erectile dysfunction (ED) is a very common condition in men. About $40 \%$ of ED cases are psychogenic Many of the psychogenic ED patients are young men. The causes of psychogenic ED can be generalized as well as situational. Psychogenic management approaches are different from organic ED. In patients with psychogenic ED, an intersystemic approach is needed for both the patient and his partner. This intersystemic approach will inspect the real cause of the problem. Intersystemic approach: The intersystemic approach not only focuses on the patient side but also on his partner. This approach provides space for partners to explore and understand their sexual life. In this article, we focus to explore a research that conducts intersystemic principle in ED management. We conclude that in psychogenic ED, an intersystematic approach is important for determining the root cause of the problem. Finding the right core cause will determine the right treatment. This therapy can combine with pharmacologic treatments. These therapies can give a better outcome for psychogenic ED.

\section{Introduction}

Psychogenic erectile dysfunction (ED) is defined as a persistent inability to achieve or maintain an erection in sexual intercourse caused by psychological and interpersonal factors [1]. The erection process is a coordination between psychological, neurological, and blood vessels [2]. There is a complexity between psychological and physiology factors. However, psychological factors also have a big role in achieving and maintaining an erection. This is the reason that ED can occur in men at a young age [3].

As many as, $40 \%$ of psychogenic ED is reported to be the cause of ED incidence in the population [4], [5]. Psychogenic ED is mostly found in young men. A study by Caskurlu et al. reported that $85.2 \%$ of 526 men under the age of 40 are struggling with psychogenic ED. As many as, $40.7 \%$ of psychogenic ED was also found at the age above 40 years [6]. This shows that psychogenic causes contribute to the increase in cases of ED.

In cases of psychogenic ED, some of the common causes are depression, anxiety, and conflict with partners [2]. The National Health and Social Life Survey reported that emotional stress is the most frequent cause of psychogenic ED with an OR of 3.56 followed by sexual coercion. Massachusetts Male Aging Study reported that pessimistic attitude is the highest cause with OR 3.89 followed by depression and dissatisfaction with the reality of life [1].

The ISSM divides the psychogenic causes of ED as generalized and situational. In generalized causes, age accompanied by decreased libido as well as a lack of intimacy can be a cause for concern. Whereas in the situational case, the cause is all conditions that can cause depression or excessive anxiety. It could be due to partner conditions, performance, or adjustment related. Sometimes, this condition is outside of sexual intercourse. It could be the loss of a job, immediate family, work performance anxiety, pressure at work, etc. [7].

The exploration of psychogenic causes must be clear and thorough to find the root of the problem. Intersystemic assessment is frequently cited by Gambescia et al. This assessment has an advantage to focus on both individual and relational point of view. Through the medical, psychosocial, and sexual life, we try to understand the dynamic of sexual problem in patients. Our goals are to establish the etiology and determine the correct management that impact on his relationship [8]. The ability of a physician to take an intersystemic and personal approach to patients can 
contribute to diagnosis and find the right therapeutic steps. The difficulty in finding psychogenic causes will affect the success of treatment, if you have found a definite cause of this psychogenic. Therapy does not always rely on drugs, although they can be combined. Interpersonal approaches, couple constructions, and cognitive reconstruction are the main things to do.

Here, we describe the intersystemic approach to psychogenic ED and its possible therapies and effectiveness based on our literature searching.

\section{Methods}

The method in this review is the traditional literature review. Actually, there is not a single study that explicitly mentions the intersystemic approach in ED management. However, this approach is implicit in some of the terms we use in our searches on the database. We conduct a search for articles on PubMed, SAGE, and Google Scholar with the keywords "psychogenic ED" and "sex therapy" or "cognitive behavioral therapy (CBT)" or "reduce anxiety."

\section{Results and Discussion}

\section{Intersystemic assessment}

In this examination, the approach taken is individual and also relational. The ability of the physician to communicate both verbally and non-verbally is needed to grasp the points of the patient's problems [9].

\section{Individual assessment}

The first and most important step at the start of the examination is to exclude the organic etiology of ED. Apart from general examinations, physical examinations, as well as routine laboratory examinations should be done [10]. In addition, physicians must collect the details of the treatment carried out by the patient, the use of drugs for either medical indications or even drug abuse [11].

Dealing with a patient with a psychogenic ED can always be begun with counseling. A counseling technique like the one proposed by O'Donoghue is behaviorally based. Most physicians working in this area agree that behavioral therapy is the best way to deal with cases like these. This method shows more benefits. In fact, many men who complain of this condition do not realize that there is psychological involvement with the incidence of this disease. The prevalence in the population is not known but it is estimated that around
$20 \%$ of sexual relationships are dysfunctional at some stage [12].

When exploring a patient's disease history, a 3P disease model needs to be applied. This model includes predisposing, precipitating, and perpetuating factors [13]. Predisposing factors can be defined as factors that should be suspected as a trigger for ED. These factors can come from environmental, social, psychological, genetic, and also the patient's family. However, the predisposing factors are not the same as the biopsychosocial model. This predisposing factor is a factor that occurs in the premorbid phase or a period where the disease has not yet appeared. This predisposing factor is a factor that occurs in the premorbid phase or a period where the disease has not yet appeared, while the precipitating factor is a factor that appears in the acute phase of the ED disease. These factors contribute to the aggravation of the disease. These factors can be psychological, socioenvironmental, and biological [13]. The last one, the perpetuating factors, these are factors that persist in of the progress of the disease. It could also be things the patient does to decrease the progress of the disease, but sometimes these actions increase the progress of the disease [14].

Sometimes, myths about men change a man's perspective on erections. This makes men worry about their performance. To confirms this perceptive, Beckwith et al. conducted a study on 91 men with 40 of them organic ED, 24 psychogenic, and 27 controls. They were asked to fill out a questionnaire about "male myths," this study focuses on seeing whether "male myths" to be the cause of psychogenic ED or the result of psychogenic ED. The result is that the perspective on "male myths" is different in each group but it is not significant. Beckwith et al. argued that if "male myths" were the cause of psychogenic disease, "male myths" should exist in every patient with psychogenic ED. However, Beckwith et al. argued that male myth is more the result of ED psychogeny rather than etiology [15]. Hence, this perception should be breaking by physician when counseling with patients.

A nocturnal erection is also needed to distinguish whether it is psychogenic or organic. The tools that can be used are the snap-gauge test or rigid scan monitor. The both methods are the same principle, that is, wearing the device before sleep for measuring nocturnal erection and then measured again on waking. Whether there is a change or not, both devices prove an erection at night [16].

Basar et al. conducted a study on 87 men who were divided into psychogenic, arterial, and venous ED. Nocturnal penile tumescence recording parameters between psychogenic and vascular ED (arterial and veno-occlusive) were compared. Basar et al. stated that nocturnal penile tumescence recording has been considered as the gold standard and, this study, it showed $90.6 \%$ sensitivity and $88.2 \%$ specificity in 
differentiating the cause of ED [17]. Other study by Wang et al. also conducted in 1169 (aged 18-67) with complaints of ED. Patients underwent AVSS-RigiScan test with the administration of phosphodiesterase-5 (PDE-5) inhibitors. At the end of study, Wang et al. suggested that AVSS-RigiScan test with oral PDE-5 inhibitors can objectively assess penile tumescence and rigidity and seems to be a better modality in differentiating psychogenic from organic ED [18].

When the possible organic causes have been eliminated, the physician must explore the psychological aspects of the patient. It is well known that there is a strong relationship between mental conditions and ED, especially depression and anxiety. The relationship between ED and depression is likely bidirectional, meaning that they can affect each other [19]. Patients with depressed tend to be self-critical or overly judgmental about their sexual performance so that depressed patients tend to have problems with their erectile function. Physiologically, erection occurs when brain and local biochemistry cause relaxation of the penile muscles resulting in tumescence. In depressed patients, there are changes in brain biochemistry that affects the autonomic nervous system, causing the inability of the penis to erect [20]. In other case, anxiety is "highly inhibitory to sexual performance." Mental anxiety will contribute to the inability to achieve an erection [21].

Physicians must be careful in recognizing psychological disorders in ED patients. Many men are not aware of the psychological aspects of their ED, including their experiences of daily stressors [22]. The surrounding culture can also shape the patient's perception of ED. The perception that men must be tough and strong so that the incidence of ED is considered demasculinization also needed to be explored because it also contributes to the confidence of the patient [23].

Other than that, the intergenerational history also needs to be assessed. The perspective about sexual topic in the family needs to be explored. This influence certainly contributes to the patient's cognitive, behavioral, and emotional views of sex. Patients who come from religious upbringing sometimes have difficulty expressing their sexual desires. These findings will also help physicians discover the dynamics in patients and facilitating the expectations that might be achieved together with patients [24].

Finally, physician can perform psychometry on patients to make objective assessment of the patient's individual factors. Instruments that can be used include (1) personality questionnaires; (2) depression inventories; and (3) questionnaires for sexual dysfunction and relationship factors [11].

\section{Relational assessment}

Examining individual factors will not be complete without assessment of patient relationship with his partner. In a study of 1873 men with range of age from 18 to 44 years old who complained about ED symptoms, men reported conflicts with their partners led to severe ED symptoms [25]. Men reported conflicts with their partners that led to severe ED symptoms [25]. This condition is bidirectional, it could be that ED causes conflict with the partner or vice versa [26]. At this stage, each partner must reexamine the concept of intimacy according to their version. Each partner's behavior must be observed and asked to his partner to see the response and feedback on the attitude. The length of the relationship as well as the age of the patients should be observed to see what they think about the quality of the sexual relationship.

During the examination, each partner must have the courage to openly reveal their feelings toward this condition including anger, anxiety, and expectations that do not come true [1]. Openness does not only occur when meeting a physician but also must be maintained in daily life. Poor communication will lead to unsuccessful therapy. It should be emphasized that anger and disappointment of the partner need to be resolved immediately and should not be buried. Such conditions will give positive results and support in patients [27].

\section{Therapy approach}

Couples seek for treatment because they are worried that this condition will affect the quality of their relationship. With an intersystemic approach, both individual factors and partners are explored holistically. The expectation is the couple which can regain the satisfaction in the relationship. The main aim in this therapy is restoring the patient's confidence as well as the patient's commitment to restart the intimacy between both of them.

\section{Pharmacological}

PDE-5 inhibitor is the initial approach for therapy with drugs. In cases with psychogenic ED, administration of PDE-5 inhibitors should be considered. Apart from the pharmacodynamics effects, PDE-5 inhibitors will increase the patient's confidence. Gradually, the use of this drug must also be reduced to a halt [13]. PDE-5 inhibitors are effective for both men and women. There have been many studies that have also carried out giving PDE-5 inhibitors to partners and reported an improvement in the quality of the relationship [28]. Administration of PDE-5 inhibitors in ED patients with depression has also been reported to improve symptoms of depression [29].

Apart from prescription of the PDE- 5 inhibitors, monitoring of other drugs is also necessary. Patients who consume antihypertensives agent such as betablockers and thiazides should be considered and tight observe. In addition, patients with anti-depressants 
should also be considered such as imipramine, amitriptyline, and clomipramine [11].

In couple who are sexually dysfunctioned or distorted, giving PDE-5 should be considered in women, not only in men. Psychogenic ED can also result from a distorted sexual relationship with his partner. Therefore, Chivers and Rosen conducted a systematic review of PDE-5 inhibitor to women. However, the results of this systematic review show a tendency that giving PDE-5 inhibitors to women do not give a significant response as well as men [30].

\section{Individual psychological therapy}

This individual psychological therapy can range from anxiety reduction and desensitization therapy, CBT, and sexual stimulation techniques.

\section{Anxiety reduction-desensitization}

Kane et al. argued that anxiety has an impact on a person's sexual function, including erection. The use of provoking anxieties has been widely researched, with some claiming to have an effect and some stating that there is no effect [31]. Anxiety reductiondesensitization is a method that has been developed for a long time in ED therapy. Since the research published by A.J. Cooper in 1968 and 1969, the use of relaxation techniques as a part of ED therapy has been successful. However, this anxiety reduction technique is still being debated because there is no standard technique for reducing anxiety in patients with ED [32]. William Master and Virginia Johnson stated about the pathophysiology of psychogenic ED, there is anxiety about sexual performance or what is known as "spectatoring", that is very important to overcome this. One of the best ways to do this is with non-genital and non-demand pleasuring exercises termed sensate focus [11].

This sensual pleasure or sensate focus is expected to reduce the stress or anxiety involved in the patient. Sensate focus can be done by means of pleasant physical contact. Couples are expected to focus on thoughts and expected results rather than the activities that carried out. If this continues to be practiced or desensitized, it is hoped that the patient will divert anxiety to a pleasant touch. This can encourage a person to reduce negative emotions and be able to fight psychological erections [33].

The physician during therapy can provide feedback from the couple about the activities that were successful and what they wish to do next. Good feedback will help the patient to be more confident and to be able to overcome anxiety [34]. Hedon gave an illustration the method how to reduce anxiety in sexual disorders (Figure 1) [35].

\section{Cognitive behavioral interventions}

The goal of therapy is to reconstruct the patient's knowledge and expectations of sexual intercourse. Selfconcept and belief in sexual performance that is wrong will aggravate the patient and even make it difficult for the patient to achieve an erection. This therapy helps the patient to identify himself as well as any concepts he has regarding pleasant sexual performance. Patients are expected to have correct knowledge about sexual activity, their own reproductive organs and their partners, sexual responses, and fantasies about themselves and their partners [11]. Behavioral therapy that is widely used is conjoin therapy. This therapy does not focus on sexual relations at the beginning but cooperation and communication between the two partners. If good communication achieved between the two partners, the success of sexual activity will work by itself [11].

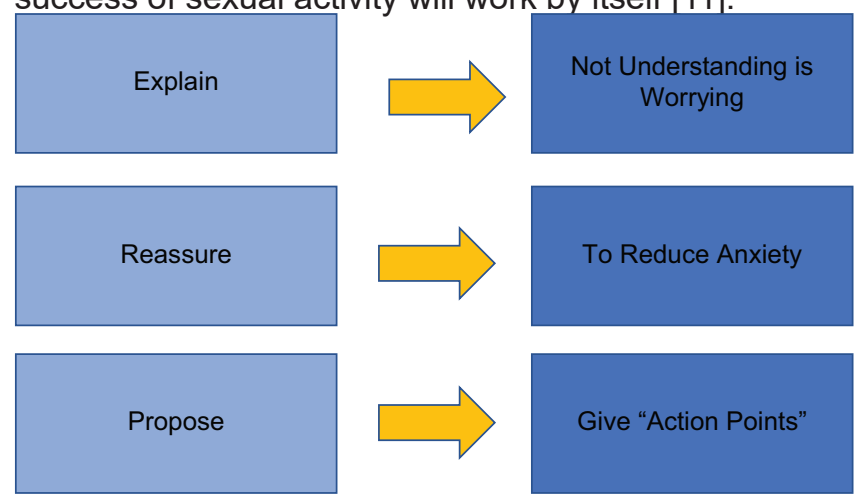

Figure 1: Methods to decrease sexual anxiety (adapted and modified from Hedon F. [35])

Bilal et al. conducted a study on 28 young men in Pakistan who were diagnosed with psychogenic ED. A total of 13 people underwent cognitive behavioral sex therapy (CBST) alone twice a week with a duration of $50 \mathrm{~min}$ for a period of $4,6,8$, and 12 weeks for the mild, mild to moderate, moderate, and severe forms, then compared with 15 people who only received 50 mg sildenafil on demand. It was found that the group with CBT showed more significant results compared to sildenafil group. They concluded that this therapy was emerging and promising treatment choice in younger men suffering from psychogenic ED. Although this study is far from being a perfect design, it is a good pilot study to show that CBT is a good solution [36]. Still from Pakistan, Khan et al. conducted the same study on 60 men who had ED. They were divided into two groups, Group 1 was the patient who received CBT, while the second group was the control. The result is that the CBT group showed greater improvement [37].

Study by Hoyer et al. conducted on 451 outpatients with sexual dysfunction. The diagnosis in this study was not specific to psychogenic ED but varied. They performed CBT on these patients. Before and after therapy, a questionnaire was administered. The results indicated a change in the overall symptoms experienced by the patient [38]. 


\section{Sexual stimulation technique}

Erection can be generated by adequate sexual stimulation. Adequate foreplay can help the patient to achieve an erection. Increased genital stimulation by partners is expected to increase erection success. The stimulation is varies, from touching with hand and can also be oral stimulation. The technique can be also used in older men [1].

In reducing anxiety, sex position and technique exercises also can be used as a reference for dealing with anxiety. Bass suggested two positions that are considered to help overcome sexual dysfunction in men, including ED. The principle of this position is that the man is asked to have control over the pace of the intercourse as well as the genital of his partner. This principle is expected to enable the patient to reduce his anxiety and able to control the intercourse [39].

Bass stated that several positions that have been proposed such as female superior (woman on top) are effective for reference in men with anxiety. The reason is the position can help man in relaxation. Besides that, this position allows the partner to lie on top so the men have a minimum effort in intercourse. Despite the fact, many men reported being uncomfortable with this position because they felt their weakness exposure in front of their partner. Similar to the male superior (missionary) position, this position also makes a man more tense in his muscles [39].

Bass suggested that men are required to stand on the side of the bed. The partner is in one of two positions: Either with hands and knees facing away from the man or lying in front of him with the hips slightly raised. In this case, the height of the penis will be parallel to the vagina so penetration can occur with slight adjustments. In this position, men with ED can see the penis penetrating into the vagina at a right angle. Standing straight during intercourse gives the patient maximum ejaculatory control and allows for slow intercourse pace. About $81 \%$ (22 of 27 from his study) stated that this position was successful in correcting complaints of sexual dysfunction [39].

\section{Psychological couples therapy}

This therapy begins with a cognitive reconstruction of the partners in their sexual function. An important initial emphasis on partners is that sexual satisfaction could not be only achieved by sexual intercourse but also can take the form of other activities [40]. Couples should also be informed that erection is not a standard of physical, mental, or sexual health or masculinity. Couples are encouraged to communicate and express each other's language of love in a variety of ways, including verbal and non-verbal.

Physicians can direct and guide communication between partners regarding the success of their current sexual life and then ask their current pessimism about it.
Understanding this condition, physicians can encourage a partner's optimism and direct partners to various relevant and easy ways to achieve sexual satisfaction [34].

In addition, physicians also help couples by debunking the myths related to sexual activity. This also includes religious and sociocultural issues that often become obstacles to achieving correct sexual function.

Hawton et al. carried out a study about sex couples therapy with 36 couples who entered physician because of male partner's ED. A positive outcome occurred in $69.4 \%$ and was associated with better pretreatment communication and sexual adjustment. The highlight of this therapy is that physician should assess the ED and its impact toward his partner. Attention might also be consider to the female partner's adjustment and hope [27].

All of these psychological therapies can be combined and presented in Table 1. This table describes the series of activities and content of counseling patients during the 12 weeks of therapy [41].

Table 1: Components of cognitive behavioral sex therapy session in psychogenic erectile dysfunction (Adapted and Modified from Nobre P and Gouveia JP [41]

\begin{tabular}{|c|c|}
\hline Session & Components \\
\hline First week & $\begin{array}{l}\text { Formulation the unique of psychosexual history. Psychosexual education } \\
\text { can be presented through lecture, video, book, or digging the myth about } \\
\text { sex. Penetration is forbidden till the therapist advises otherwise }\end{array}$ \\
\hline Second week & Reconstruction of sexual attitudes \\
\hline Third week & $\begin{array}{l}\text { Digging the perceptive catastrophization (performance demand and } \\
\text { failure anticipation) }\end{array}$ \\
\hline Fourth week & $\begin{array}{l}\text { Relaxation exercise (mindful breathing) and mindfulness } \\
\text { (nonjudgmental, present moment focus approach). Help patients to } \\
\text { control negative emotion with relaxation technique in home. Homework } \\
\text { assignment: Spending time with partner with non-sexual activation } \\
\text { (sharing about work, childhood, etc.) }\end{array}$ \\
\hline Fifth week & $\begin{array}{l}\text { Learning sexual communication and love skills (spending time together, } \\
\text { emotional expression, love talk, surprise gifts). Homework assignment: } \\
\text { Exploring the body of partner personally (pay attention to emotions and } \\
\text { thoughts in a nonsexual manner) }\end{array}$ \\
\hline Sixth week & $\begin{array}{l}\text { Evaluation of relaxation exercises and mindfulness that have done in } \\
\text { home. Homework assignment: Exercise sensate focus I; client asked to } \\
\text { play with his partner. Giving attention to partner's body except and breast. } \\
\text { Learn to communicate about his pleasure to his partner. If the patient and } \\
\text { his partner reach a high level of sexual arousal, they may have an orgasm, } \\
\text { but separately. This new experience can communicate to his partner. }\end{array}$ \\
\hline Seventh week & $\begin{array}{l}\text { Evaluation of love and sexual communication skills. Homework } \\
\text { assignment: Exercise sensate focus II; patient asked to give and receive } \\
\text { stimulation on his/her body includes genital and breast. The patient and his } \\
\text { partner reach a high level of sexual arousal, they may have an orgasm, but } \\
\text { separately. Then, this new experience is communicated to his partner. }\end{array}$ \\
\hline Eighth week & $\begin{array}{l}\text { Evaluation of exercise sensate focus I and II. Homework assignment: } \\
\text { Try to do "start and stop technique;" the patient ask his partner to } \\
\text { stimulate his penile to achieve erection. Then, stop until penile flaccid. } \\
\text { Repeat this exercise } 3 \text { times. Here, both partners can achieve orgasm } \\
\text { but not through sexual intercourse. This exercise demonstrates that } \\
\text { it is not necessary that a man constantly maintains the erection once } \\
\text { reached (cognitive restructuring of a myth). }\end{array}$ \\
\hline Ninth week & $\begin{array}{l}\text { Homework Assignment: Now try "start and stop technique" with a } \\
\text { lubricant; the patient demands that his partner use a lubricant to } \\
\text { stimulate his penis until it forms an erection, then avoid stimulating until } \\
\text { the penis becomes flaccid; perform the exercise } 3 \text { times. Both partners } \\
\text { can experience orgasm in this situation, but they must do so separately. } \\
\text { This exercise shows that erection can be lost, but it can be restored, } \\
\text { and it produces a warm and moist sensation (similar to the vaginal wall). }\end{array}$ \\
\hline Tenth week & $\begin{array}{l}\text { Evaluation of "start and stop technique." Homework assignment: } \\
\text { Undemanding sexual intercourse. When the patient learns to get erection, } \\
\text { his partner penetrates the erect penis into her vagina, slowly progressing } \\
\text { to climax by making few gentle movements. The patient's partner } \\
\text { removes herself from him before ejaculation. The patient eventually } \\
\text { learns that penetration is not necessary for sexual satisfaction in every } \\
\text { encounter, releasing the pressure to get an erection off the mind of client. }\end{array}$ \\
\hline Eleventh week & $\begin{array}{l}\text { Evaluation of home assignments and discussion about hot issues. Now, } \\
\text { patients allowed for sexual penetration. }\end{array}$ \\
\hline Twelve week & $\begin{array}{l}\text { Termination of therapy, evaluation of therapy goals and outcomes } \\
\text { post-treatment. }\end{array}$ \\
\hline
\end{tabular}




\section{Combination therapy}

Monotherapy of PDE-5 inhibitor sometimes does not work. Monotherapy of PDE-5 inhibitor sometimes does not work, although using this drug at the beginning can help increase patients confidence. Is there any possibility of combining these two therapeutic methods? Before giving an explanation regarding it. We include a comparative study of pharmacology to psychology therapeutic. An interesting study by Baum et al. comparing the use of prostaglandin $\mathrm{E} 1$ with sex therapy. A total of 50 men with this diagnosis were divided into two groups. The first group received standard sex therapy for 12 weeks and Group 2 used the low-dose $(2.5 \pm 5.0 \mathrm{mg}) \mathrm{PGE}-1$. The result was that $47 \%$ of patients with PGE-1 experienced an increase in erection while $58 \%$ of patients with sex therapy. About $69 \%$ of patients with PGE-1 were satisfied with their treatment and $75 \%$ with sex therapy were satisfied with their treatment. However, the advantages of PGE-1 are the longer erection duration than sex therapy (35 min vs. $10 \mathrm{~min}$ ) and the cost of the PGE-1 cheaper than sex therapy [42].

Banner and Anderson conducted a study on 53 couples who tested sildenafil alone or an integrative treatment protocol (ITP) with sildenafil and CBST for the first 4 weeks. At the end of week 4, the sildenafil group was added CBST while ITP patients continued to carry out the procedure. The results of this study indicate that CBST has a very positive effect within 8 weeks of treatment and even in patients with sildenafil who have been combined with this CBST [43].

Pharmacologic treatment alone is not always satisfactory. Combination therapy should be considered. Counseling ED (psychology therapy) patients and prescribing them with sildenafil are reported to be better than sildenafil alone. This was also confirmed by Melnik et al. in a meta-analysis study comparing the efficacy of sildenafil versus psychotherapy plus sildenafil citrate, the results obtained were that the combination of the two gave better results than sildenafil alone [44].

\section{Conclusion}

Psychogenic ED is found in $40 \%$ of all ED cases. This case is mostly found in young men who suffer from ED. Not many studies have analyzed the use of intersystemic assessment in psychogenic ED patients. The diagnostic approach to psychogenic ED is different from organic ED. In psychogenic ED, an intersystematic approach is needed to determine the root cause of the problem. Finding the right core cause will determine the right treatment. Treatment with sildenafil should be considered in combination with a psychological approach. Effective results are expected with psychological therapy plus sildenafil instead of sildenafil alone.

\section{Acknowledgments}

The authors thank to Raditya Ibrahim and Edwina Kartika Risda for providing input and language corrections to this article.

\section{References}

1. Rosen RC. Psychogenic erectile dysfunction. Classification and management. Urol Clin North Am. 2001;2(2):269-78.

PMid: 11402580

2. Nguyen HMT, Gabrielson AT, Hellstrom WJG. Erectile dysfunction in young men a review of the prevalence and risk factors. Sex Med Rev. 2017;5(4):508-20. https://doi. org/10.1016/j.sxmr.2017.05.004

PMid:28642047

3. Shamloul R, Ghanem H. Erectile dysfunction. Lancet 2013;381(9861):153-65. https://doi.org/10.1016/ s0140-6736(12)60520-0

4. Aydin S, Ünal D, Erol H, Karaman I, YIlmaz Y, Sengül E, et al. Multicentral clinical evaluation of the aetiology of erectile dysfunction: A survey report. Int Urol Nephrol. 2001;32(4):699-703

PMid:11989568

5. Melman A, Tiefer L, Pedersen R. Evaluation of first 406 patients in urology department based center for male sexual dysfunction. Urology. 1988;32(1):6-10. https://doi. org/10.1016/0090-4295(88)90443-8

PMid:3388663

6. Caskurlu T, Tasci Al, Resim S, Sahinkanat T, Ergenekon E. The etiology of erectile dysfunction and contributing factors in different age groups in Turkey. Int J Urol. 2004;11(7):525-9. https://doi.org/10.1111/j.1442-2042.2004.00837.x PMid:15242362

7. Papagiannopoulos D, Khare N, Nehra A. Evaluation of young men with organic erectile dysfunction. Asian J Androl. 2015;17(1):11-6. https://doi.org/10.4103/1008-682x.139253 PMid:25370205

8. Gambescia N, Sendak SK, Weeks G. The treatment of erectile dysfunction. J Fam Psychother. 2009;20(2-3):221-40.

9. Bancroft J. Lecture 4: Psychogenic erectile dysfunction a theoretical approach. Int J Impot Res. 2000;12:S46-8. https:// doi.org/10.1038/sj.ijir.3900561

PMid:11002401

10. Padma-Nathan H. Sildenafil citrate (Viagra) treatment for erectile dysfunction: An updated profile of response and effectiveness. Int J Impot Res. 2006;18(5):423-31. https://doi.org/10.1038/ sj.ijir.3901492

PMid:16810179

11. Bodie JA, Beeman WW, Monga M. Psychogenic erectile dysfunction. Int J Psychiatry Med 2003;33(3):273-93. https:// doi.org/10.2190/nhv6-3dyb-x51g-4bvm

PMid: 15089008 
12. O'DonoghueF.Psychological managementoferectiledysfunction and related disorders. Int J Std AIDS. 1996;7(Suppl 3):9-12. https://doi.org/10.1258/0956462961918004

13. Wright $C D$, Tiani AG, Billingsley AL, Steinman SA, Larkin $K T$, McNeil DW. A framework for understanding the role of psychological processes in disease development, maintenance, and treatment: The 3P-disease model. Front Psychol. 2019;10:2498. https://doi.org/10.3389/fpsyg.2019.02498 PMid:31824367

14. Farre JM, Fora F, Lasheras MG. Specific aspects of erectile dysfunction in psychiatry. Int J Impot Res. 2004;16(Suppl 2):469. https://doi.org/10.1038/sj.ijir.3901243

PMid:15496858

15. Beckwith ACE, Green J, Goldmeier D, Hetherton J. Dysfunctional ideas ("male myths") are a result of, rather than the cause of, psychogenic erectile dysfunction in heterosexual men. Int J Std AIDS. 2009;20(9):638-41. https://doi.org/10.1258/ ijsa.2008.008468

PMid:19710338

16. Rajiah K, Veettil SK, Kumar S, Mathew EM. Psychological impotence: Psychological erectile dysfunction and erectile dysfunction causes, diagnostic methods and management options. Sci Res Essays. 2012;7(4):446-52. https://doi. org/10.5897/sre11.1065

17. Basar MM, Atan A, Tekdogan ÜY. New concept parameters of rigiscan in differentiation of vascular erectile dysfunction: Is it a useful test? Int J Urol. 2001;8(12):686-91. https://doi. org/10.1046/j.1442-2042.2001.00398.x

PMid:11851769

18. Wang T, Zhuan L, Liu Z, Li MC, Yang J, Wang SG, et al. Audiovisual sexual stimulation and rigiscan test for the diagnosis of erectile dysfunction. Chin Med J (Engl). 2018;131(12):146571. https://doi.org/10.4103/0366-6999.233945 PMid:29893364

19. Araujo AB, Durante R, Feldman HA, Goldstein I, Mckinlay JB. The relationship between depressive symptoms and male erectile dysfunction: Cross-sectional results from the Massachusetts male aging study. Psychosom Med. 1998;60(4):458-65. https:// doi.org/10.1097/00006842-199807000-00011

PMid:9710291

20. Kaplan HS. New sex therapy: Active treatment of sexual dysfunctions. In: New Sex Ther Act Treat Sex Dysfunctions. Taylor and Francis Group: New York; 2013. p. 1-544. https://doi.org/10.4324/9780203727317-12

21. Reynolds B. Psychological treatment of erectile dysfunction in men without partners: Outcome results and a new direction. J Sex Marital Ther. 1991;17(2):136-46. https://doi. org/10.1080/00926239108404955

PMid:1920469

22. Perelman $M$, Shabsigh $R$, Seftel $A$, Althof $S$, Lockhart $D$. Attitudes of men with erectile dysfunction: A crossnational survey. J Sex Med. 2005;2(3):397-406. https://doi. org/10.1111/j.1743-6109.2005.20355.x PMid:16422872

23. DiMeo PJ. Psychosocial and relationship issues in men with erectile dysfunction. Urol Nurs. 2006;26(6):442-6, 453; quiz 447.

PMid:17253078

24. Mcfarland MJ, Uecker JE, Regnerus MD, Mcfarland MJ, Uecker JE, Regnerus MD. The role of religion in shaping sexual frequency and satisfaction: Evidence from married and unmarried older. J Sex Res. 2011;48(2-3):297-308. https://doi. org/10.1080/00224491003739993

PMid:20349390

25. Boddi V, Fanni E, Castellini G, Fisher AD, Corona G, Mario M.
Conflicts within the family and within the couple as contextual factors in the determinism of male sexual dysfunction. J Sex Med. 2015;12(12):2425-35. https://doi.org/10.1111/jsm.13042 PMid:26608700

26. Dean J, de Boer BJ, Graziottin A, Hatzichristou D, Heaton J, Tailor A. Partner satisfaction and successful treatment outcomes for men with erectile dysfunction (ED). Eur Urol Suppl. 2006;5(13):779-85. https://doi.org/10.1016/j. eursup.2006.06.006

27. Hawton K, Catalan J, Fagg J. Sex therapy for erectile dysfunction: Characteristics of couples, treatment outcome, and prognostic factors. Arch Sex Behav. 1992;21(2):161-75. https:// doi.org/10.1007/bf01542591

PMid:1580787

28. Heiman JR, Talley DR, Bailen JL, Oskin TA, Rosenberg SJ, Pace CR, et al. Sexual function and satisfaction in heterosexual couples when men are administered sildenafil citrate (Viagra ${ }^{\circledR}$ ) for erectile dysfunction: A multicentre, randomised, double-blind, placebo-controlled trial. BJOG. 2007;114(4):437-47. https://doi. org/10.1111/j.1471-0528.2006.01228.x

PMid: 17284249

29. Mccabe MP, Althof SE. A Systematic review of the psychosocial outcomes associated with erectile dysfunction: Does the impact of erectile dysfunction extend beyond a man's inability to have sex? J Sex Med. 2014;11(2):347-63. https://doi.org/10.1111/ jsm.12374

PMid:24251371

30. Chivers ML, Rosen RC. Phosphodiesterase Type 5 inhibitors and female sexual response: Faulty protocols or paradigms? J Sex Med. 2010;7(2 PT 2):858-72. https://doi. org/10.1111/j.1743-6109.2009.01599.x

PMid:19929916

31. Kane L, Dawson SJ, Shaughnessy K, Reissing ED, Ouimet AJ, Ashbaugh AR. A review of experimental research on anxiety and sexual arousal: Implications for the treatment of sexual dysfunction using cognitive behavioral therapy. J Exp Psychopathol. 2019;10(2):1-24. https://doi. org/10.1177/2043808719847371

32. Norton GR, Jehu D. The role of anxiety in sexual dysfunctions: A review. Arch Sex Behav. 1984;13(2):165-83. https://doi. org/10.1007/bf01542150

PMid:6145405

33. LueTF. Erectiledysfunction. NEnglJ Med. 2000;342(24):1802-13. PMid:10853004

34. Gambescia N, Sendak SK, Weeks GR. The treatment of erectile dysfunction in systemic sex therapy. In: Hertlein KM, Weeks GR, Gambescia N, editors. New York, London: Taylor and Francis Group; 2009. p. 108-26. https://doi.org/10.4324/9780203876930

35. Hedon F. Anxiety and erectile dysfunction: A global approach to ED enhances results and quality of life. Int J Impot Res. 2003;15(Suppl 2):16-9. https://doi.org/10.1038/sj.ijir.3900994 PMid: 12825100

36. Bilal A, UI Hasan Abbasi N. Cognitive behavioral sex therapy: An emerging treatment option for nonorganic erectile dysfunction in young men: A feasibility pilot study. Sex Med. 2020;8(3):396407. https://doi.org/10.1016/j.esxm.2020.05.005 PMid:32591219

37. Khan S, Amjad A, Rowland D. Cognitive behavioral therapy as an adjunct treatment for Pakistani men with ED. Int J Impot Res. 2017;29(5):202-6. https://doi.org/10.1038/ijir.2017.23 PMid:28701798

38. Hoyer J, Uhmann S, Rambow J, Jacobi F. Reduction of sexual dysfunction: By-product of cognitive-behavioural therapy for psychological disorders? Sex Relatsh Ther. 2009;24(1):64-73. https://doi.org/10.1080/14681990802649938 
39. Bass BA. Two positions for sexual intercourse useful in the treatment of male sexual dysfunction. Fam J. 2000;8(4):416-8. https://doi.org/10.1177/1066480700084016

40. Fucito LM. Integrating medication, realistic expectations, and therapeutic interventions in the treatment of male sexual dysfunction. J Sex Marital Ther. 2005;31(4):319-28. https://doi. org/10.1080/00926230590950226

PMid:16020149

41. Nobre P, Gouveia JP. Erectile dysfunction: An emperical approach based on Beck's cognitive theory. Sex Relatsh Ther. 2000;15(4):351-66. https://doi.org/10.1080/713697434

42. Baum N, Randrup E, Junot D, Hass S. Prostaglandin E1 versus sex therapy in the management of psychogenic erectile dysfunction. Int J Impot Res. 2000;12(3):191-4. https://doi. org/10.1038/sj.ijir.3900544

PMid:11045914

43. Banner LL, Anderson RU. Integrated sildenafil and cognitivebehavior sex therapy for psychogenic erectile dysfunction: A pilot study. J Sex Med. 2007;4(4 Pt II):1117-25. https://doi. org/10.1111/j.1743-6109.2007.00535.x PMid:17627724

44. Melnik T, Soares BG, Nasello AG. The effectiveness of psychological interventions for the treatment of erectile dysfunction: Systematic review and meta-analysis, including comparisons to sildenafil treatment, intracavernosal injection, and vacuum devices. J Sex Med. 2008;5(11):2562-74. https:// doi.org/10.1111/j.1743-6109.2008.00872.x

PMid: 18564156 